\title{
The Effect of Nursing Care Applied to Patients with Chronic Obstructive Pulmonary Disease on Their Sexual Experiences and Quality of Life
}

\author{
Fatma Karasu ${ }^{1}$ (D) . Canan Birimoğlu Okuyan² ${ }^{\text {ID }}$
}

Accepted: 21 January 2021 / Published online: 19 March 2021

(c) The Author(s), under exclusive licence to Springer Science+Business Media, LLC part of Springer Nature 2021

\begin{abstract}
This study was conducted for the aim of assessing the effect of nursing care applied to patients with chronic obstructive pulmonary disease on their sexual experiences and quality of life. The sample of the study was determined via power analysis, patients were assigned groups using a simple random sampling method. The data were collected between December 2019-June 2020. The researcher applied the nursing care to patients in the experimental group in their home three times. There was a statistically significant difference between posttest mean scores of the Short Form-36 Health-Related Quality of Life Questionnaire subscales and Arizona Sexual Experiences Scale of the patients in the experimental and control groups $(p<0.05)$. In this study, it was determined that there was an increase in the Health-Related Quality of Life Questionnaire mean score of patients with COPD after the nursing care; whereas, there was a slight decrease in the Arizona Sexual Experiences Scale mean score.
\end{abstract}

Keywords COPD · Nursing care · Quality of life · Sexual experiences · Turkey

\section{Introduction}

Being ranked as the first among the reasons of morbidity and mortality worldwide, Chronic Obstructive Pulmonary Disease (COPD) is estimated to be the third most common cause of death by 2020 [1,2]. Also, the number of COPD patients is more than 600 million in the world and approximately 2-3 million in Turkey [3].

In COPD, a progressive but also preventable and curable disease [2], symptoms such as dyspnoea, coughing, increased phlegm, fatigue, sleep disorders, and muscle weakness are

Fatma Karasu

fatmakarasu@kilis.edu.tr

Canan Birimoğlu Okuyan

cananbirimoglu@gmail.com; cananbirimoglu@subu.edu.tr

1 Department of Nursing, Yusuf Şerefoğlu Faculty of Health Sciences, Kilis 7 Aralık University, Kilis, Turkey

2 Department of Nursing, Faculty of Health Sciences, Sakarya University of Applied Sciences, Sakarya, Turkey 
frequently encountered symptoms that affect an individual's quality of life negatively [4]. In studies examining the quality of life in COPD, it has been determined that as the disease progresses, the severity of symptoms such as increased airflow limitation and dyspnoea level increases, thus causing impairment in an individual's quality of life [5]. Another critical problem hurting the quality of life in patients with COPD and being neglected is sexual function problems such as lack of sexual drive, sexual arousal, and sexual intercourse (coitus) [6]. This condition not only impairs quality of life but also destroys communication between couples and complicates patients' compliance with treatment [7,8]. A study found that the majority of male COPD patients (74\%) had at least one sexual dysfunction, and the rate of erectile dysfunction ranged from 75 to $87 \%$ [9]. Although the literature's data focus on sexual dysfunctions encountered among men, some evidence shows that respiratory system diseases in women can be accompanied by sexual dysfunction [8]. A study reported that female COPD patients had less sexual desire and impaired quality of sexual life [10].

Healthcare professionals need to examine the physical complaints and sexual problems of COPD patients when assessing them integrated, in terms of their quality of life and quality of care. The results of the study are thought to form a basis for other studies in the literature and make a contribution to nursing science. As no studies on this subject have been encountered, this study is original. Based on these results, the study was conducted to assess the effect of nursing care applied to patients with chronic obstructive pulmonary disease on their sexual experiences and quality of life.

\section{Hypotheses of the Study}

$\mathbf{H}_{\mathbf{0 - a}}:$ Nursing care does not affect the quality of life in COPD patients.

$\mathbf{H}_{\mathbf{0 - b}}$ : Nursing care does not affect sexual experiences in COPD patients.

$\mathbf{H}_{1-\mathbf{a}}$ : Nursing care affects the quality of life in COPD patients.

$\mathbf{H}_{\mathbf{1 - b}}$ : Nursing care affects sexual experiences in COPD patients.

\section{Materials and Methods}

\section{Study Design}

This study was designed as a real trial model with the pretest-posttest control group.

The study was conducted in two public hospital in Gaziantep between December 2019 and June 2020. The population consisted of adult patients diagnosed with COPD. The sample size of the study was determined as 84 COPD patients at a confidence interval of $95 \%$ using the G. Power-3.1.9 programme. The patients were randomly divided into two groups as experimental and control. They were chosen by using the table of random numbers based on a simple random sampling method. Considering possible patient losses that is death or withdrawal from the study, the study was started with 48 patients in the experimental group and 48 patients in the control group. The flow diagram of the study was shown in Fig. 1.

\section{Inclusion Criteria}

The patients were included in the study if they met the following inclusion criteria:

- Diagnosed with COPD for at least six months or more,

- Aged between 18 and 65 years and being voluntary to participate in the study, 


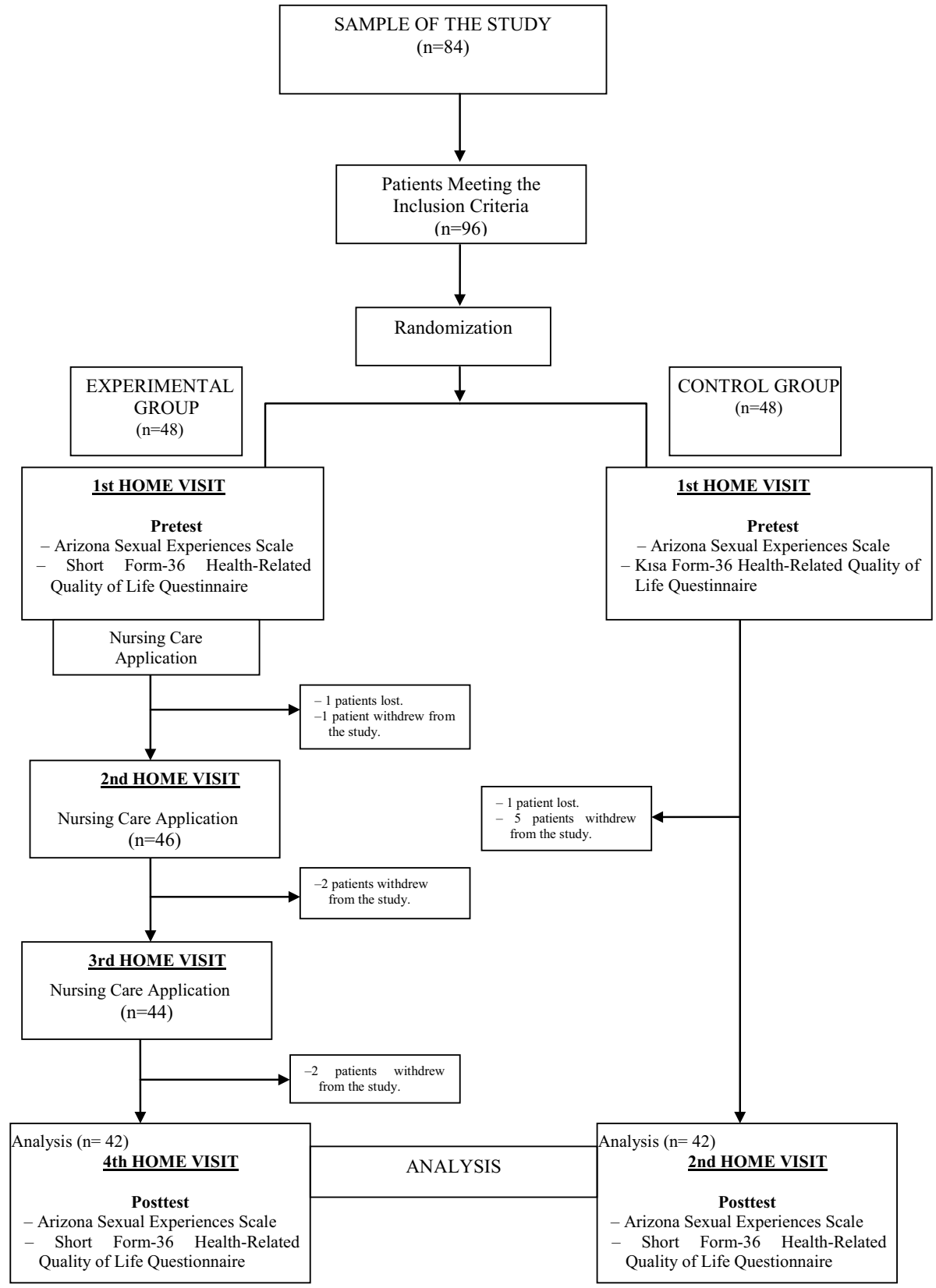

Fig. 1 The flow diagram of the study 
- Having no communication problem,

- Being at least literate and speaking Turkish.

\section{Exclusion Criteria}

- The patients were excluded from the study if they met the following exclusion criteria:

- Not agreeing to participate in the study,

- Having a cognitive disorder,

- Having a communication problem, not speaking Turkish and having a hearing-visual impairment,

- Having an advanced pulmonary or cardiac disease,

- Diagnosed with cancer.

\section{Data Collection Tools}

The data were collected using an Introductory Information Form, including information about the disease history of COPD patients, the Arizona Sexual Experiences Scale, and the Short-Form Health Survey Questionnaire (SF-36).

Introductory Information Form: This form was prepared by the researchers. The form also includes 10 questions about some descriptive characteristics like the stage of COPD, age, gender, educational background, job, and state of receiving training on COPD before [3, 7, 11]. Arizona Sexual Experiences Scale (ASES); Developed by McGahuey et al. in 2000, the scale assesses five essential components of sexual functioning as drive, arousal, penile erection/vaginal lubrication, ability to reach orgasm, and satisfaction with orgasm. While low scores refer to a strong, easy and satisfying sexual response, high scores indicate the presence of sexual dysfunction. Higher scores signify more significant sexual dysfunctions [12]. Turkish validity and reliability study of ASES was carried out by Soykan in 2004. Cronbach's alpha values of ASES were found to be 0.89 and 0.90 [13]. In this study, Cronbach's alpha value was calculated as 0.84. Short Form-36 (SF-36) Health-Related Quality of Life Questionnaire: The questionnaire was developed by Ware et al., in 1992 to evaluate the quality of life [14]. Turkish validity and reliability of SF-36 were conducted by Kocyigit et al. [15]. The lowest score signifies the worst health condition. In its Turkish validity and reliability study, the Cronbach's alpha values of the subscales were $0.73-0.76$. In the present study, Cronbach's alpha values were determined to be $0.78-0.81$.

\section{Data Collection}

The patients were visited at their homes between December 2019 and June 2020 in order to collect the data. The questionnaire and scales were applied by the researchers. The data collection forms took 15 min to complete. The pretest-posttest data were collected with 90 days interval.

\section{Nursing Intervention}

All the patients were informed about the aim of the study by phone. After that, a day/hour was set for first home visits to be paid to patients who agreed to participate in the study. Nursing care was provided during home visits made by the researcher for patients in the 
experimental group in the weeks specified. Nursing diagnoses were determined in line with patients' complaints caused by the disease. Goals were determined, and nursing interventions were applied for each nursing diagnosis.

The diagnosis system of the North American Nursing Diagnosis Association was used to diagnose the patients. These nursing diagnoses are ineffectiveness in airway cleaning, change in nourishment: eating less than what body needs and activity intolerance, change in intestinal discharge: constipation, sleep pattern disorder, sexual pattern ineffectiveness, pain, fatigue, infection risk, social isolation, lack of self-care syndrome, lack of knowledge, anxiety, lack of fluid volume, the abundance of fluid volume and change in comfort. Interventions were applied according to each nursing diagnosis determined.

\section{Experimental Group}

During the first home visit, after the nursing diagnoses of the patients were identified, nursing interventions were applied for the diagnoses. The patient was told how to adapt to physical and psychological changes caused by COPD and to possible problems. This visit lasted for about $40 \mathrm{~min}$. During the second (2 weeks later) and third home visits (4 weeks after the second visit), the nursing diagnoses were determined, and nursing interventions were applied for the problems determined during the second and third home visits. Each visit lasted for approximately $40 \mathrm{~min}$. During the fourth home visit (90 days after the first visit), the nursing care was applied in line with patients' demands. The visit lasted for approximately $30 \mathrm{~min}$.

\section{Control Group}

During the first home visit, no nursing care was applied. During the second home visit (90 days after the first visit), nursing care was applied to patients with chronic obstructive pulmonary disease following the posttest.

\section{Care Guideline}

The guideline mentions about the definition, reasons, symptoms, treatment and care of COPD, quitting smoking, proper and the regular use of COPD medications, participating in pulmonary rehabilitation programs, coughing and deep breathing exercises, protection from respiratory tract infections, proper nourishment and adequate hydration, use of oxygen therapy, controlling attacks, keeping away from stress, having regular health check-ups and arranging daily activities. The date of the next visit was determined at the end of each visit.

Any statistical significance was not determined between the experimental and control groups, in terms of stage of COPD, age average, gender, educational background, working condition, income status, smoking status, and state of getting information about COPD before $(p>0.05)$ (Table 1).

\section{Data Assessment}

The data were statistically analyzed through the SPSS 24.0 software program. The Shapiro Wilk test was used to examine whether or not the data were normally distributed, and the Cronbach's alpha was employed to examine internal consistency. The data were analyzed 
Table 1 Comparison of control variables of the experimental and control groups $(n=84)$

\begin{tabular}{|c|c|c|c|c|c|}
\hline \multirow[t]{2}{*}{ Descriptive characteristics } & \multicolumn{2}{|c|}{ Experimental group $(n=42)$} & \multicolumn{2}{|c|}{ Control group $(n=42)$} & \multirow[t]{2}{*}{ Significance } \\
\hline & Number & Percentage & Number & Percentage & \\
\hline \multicolumn{6}{|l|}{ Stage of $C O P D$} \\
\hline Stage 1 & 4 & 9.5 & 3 & 7.1 & $p=0.881$ \\
\hline Stage 2 & 25 & 59.5 & 26 & 61.9 & $\mathrm{~F}=0.022$ \\
\hline Stage 3 & 10 & 23.8 & 10 & 23.8 & \\
\hline Stage 4 & 3 & 7.1 & 3 & 7.1 & \\
\hline \multicolumn{6}{|l|}{ Gender } \\
\hline Female & 8 & 19.0 & 14 & 33.3 & $\begin{array}{l}\mathrm{x}^{2}=2.217 \\
p=0.107\end{array}$ \\
\hline Male & 34 & 81.0 & 28 & 66.7 & \\
\hline \multicolumn{6}{|l|}{ Educational background } \\
\hline Literate & 14 & 33.3 & 21 & 50.0 & $\begin{array}{l}\mathrm{x}^{2}=2.400 \\
p=0.092\end{array}$ \\
\hline$\geq$ Primary education & 28 & 66.7 & 21 & 50.0 & \\
\hline \multicolumn{6}{|l|}{ Working condition } \\
\hline Yes $^{\mathrm{d}}$ & 3 & 9.5 & 2 & 4.8 & $\begin{array}{l}\mathrm{x}^{2}=0.718^{\mathrm{b}} \\
p=0.338\end{array}$ \\
\hline No & 38 & 90.5 & 40 & 95.2 & \\
\hline \multicolumn{6}{|l|}{ Income status } \\
\hline Good & - & - & 4 & 9.5 & $\begin{array}{l}\mathrm{x}^{2}=2.467^{\mathrm{b}} \\
p=0.059\end{array}$ \\
\hline Medium & 25 & 59.5 & 35 & 83.3 & \\
\hline $\mathrm{Bad}$ & 17 & 40.5 & 3 & 7.1 & \\
\hline \multicolumn{6}{|l|}{ Smoking status } \\
\hline No, I have never smoked & 8 & 19.0 & 17 & 40.5 & $\begin{array}{l}\mathrm{x}^{2}=5.001 \\
p=0.054\end{array}$ \\
\hline I had smoked before & 22 & 52.4 & 20 & 47.6 & \\
\hline I still smoke & 12 & 28.6 & 5 & 11.9 & \\
\hline \multicolumn{6}{|c|}{$\begin{array}{l}\text { State of having obtained infor- } \\
\text { mation about COPD before }\end{array}$} \\
\hline Yes & 5 & 11.9 & 4 & 9.5 & $\begin{array}{l}\mathrm{x}^{2}=0.124^{\mathrm{b}} \\
p=0.500\end{array}$ \\
\hline \multirow[t]{3}{*}{ No } & 37 & 88.1 & 38 & 90.5 & \\
\hline & \multicolumn{2}{|c|}{ Experimental group } & \multicolumn{2}{|c|}{ Control group } & Significance \\
\hline & \multicolumn{2}{|l|}{$\mathrm{X} \pm \mathrm{SD}$} & \multicolumn{2}{|l|}{$\mathrm{X} \pm \mathrm{SD}$} & \\
\hline Age average (year) & $60.72 \pm 4.73$ & & $61.95 \pm 2$ & & $\begin{array}{l}\mathrm{F}=2.001^{\mathrm{c}} \\
p=0.617\end{array}$ \\
\hline
\end{tabular}

$* p<0.05$

${ }^{\mathrm{a}}$ Chi-square test

${ }^{\mathrm{b}}$ Fisher's exact test

${ }^{\mathrm{c}}$ ANOVA test

${ }^{\mathrm{d}}$ They work as workers 
using dependent and independent samples $t$-test, chi-square, and one-way analysis of variance (ANOVA). When interpreting the results, the significance level was taken as $p<0.05$.

\section{Ethical Considerations}

Ethical approval was obtained from the Clinical Trials Ethics Committee (Ethics Committee No: 2019/23). Written permission was obtained from the institutions from which patient data would be acquired. After giving information about the study, the participants signed the Informed Consent. We did not intervention applied to the control group and after applying the posttest to the groups, the care guideline was distributed to patients in the control group. The research was planned and conducted in accordance with the Helsinki Declaration Principles.

\section{Results}

When comparing the pretest mean scores of the ASES and SF-36 Health-Related Quality of Life Questionnaire subscales of patients in the experimental and control groups, no statistically significant difference was determined between the groups $\left(p^{>} 0.05\right)$. Upon the comparison of the posttest mean scores of ASES and SF-36 Health-Related Quality of Life Questionnaire subscales between the patients in the experimental and control groups, a statistically significant difference was found between the two mean scores $(p<0.05)$ (Table 2).

When the pretest-posttest mean scores of the ASES and SF-36 Health-Related Quality of Life Questionnaire Subscales of patients in the experimental group were compared, it was determined that patients' posttest mean scores increased and there was a statistically significant difference between the two mean scores $(p<0.05)$. Based on the comparison of the pretest-posttest mean scores of the SF-36 Health-Related Quality of Life Questionnaire general health, vitality/energy, social functioning, emotional role functioning, mental health and bodily pain subscales of patients in the control group, patients' posttest mean scores decreased and the difference between the two mean scores was statistically significant $(p<0.05)$. Also, when comparing mean scores of the ASES and SF-36 Health-Related Quality of Life Questionnaire physical functioning and physical role functioning subscales of the patients in the control group, any significant correlation was not found between the pretest-posttest mean scores ( $\left.p^{>} 0.05\right)$ (Table 3).

\section{Discussion}

One of the most important reasons for morbidity and mortality across the world is chronic obstructive pulmonary disease. Patients with COPD face many symptoms, primarily dyspnoea, throughout their disease, which affects their sexual and life quality negatively. The studies have revealed that care makes a positive contribution to the quality of life of patients with COPD $[1,16]$. In COPD patients, sexual life problems are among the most critical problems affecting the quality of life negatively [7]. However, studies on sexual experiences have mainly focused on determining men's erectile dysfunction [7, 9, 17]. Here, the findings of the study were discussed in light of the literature to determine the effect of nursing care applied to patients with the chronic obstructive pulmonary disease 


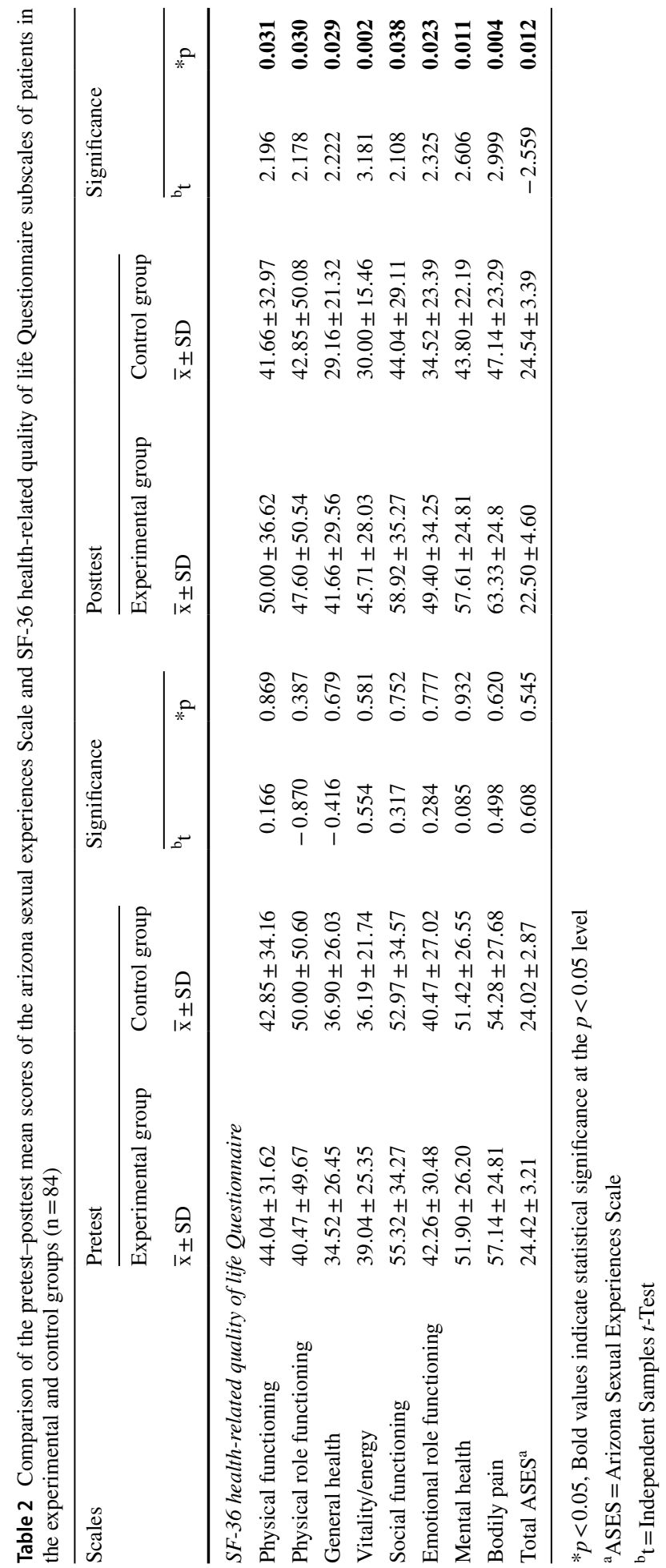




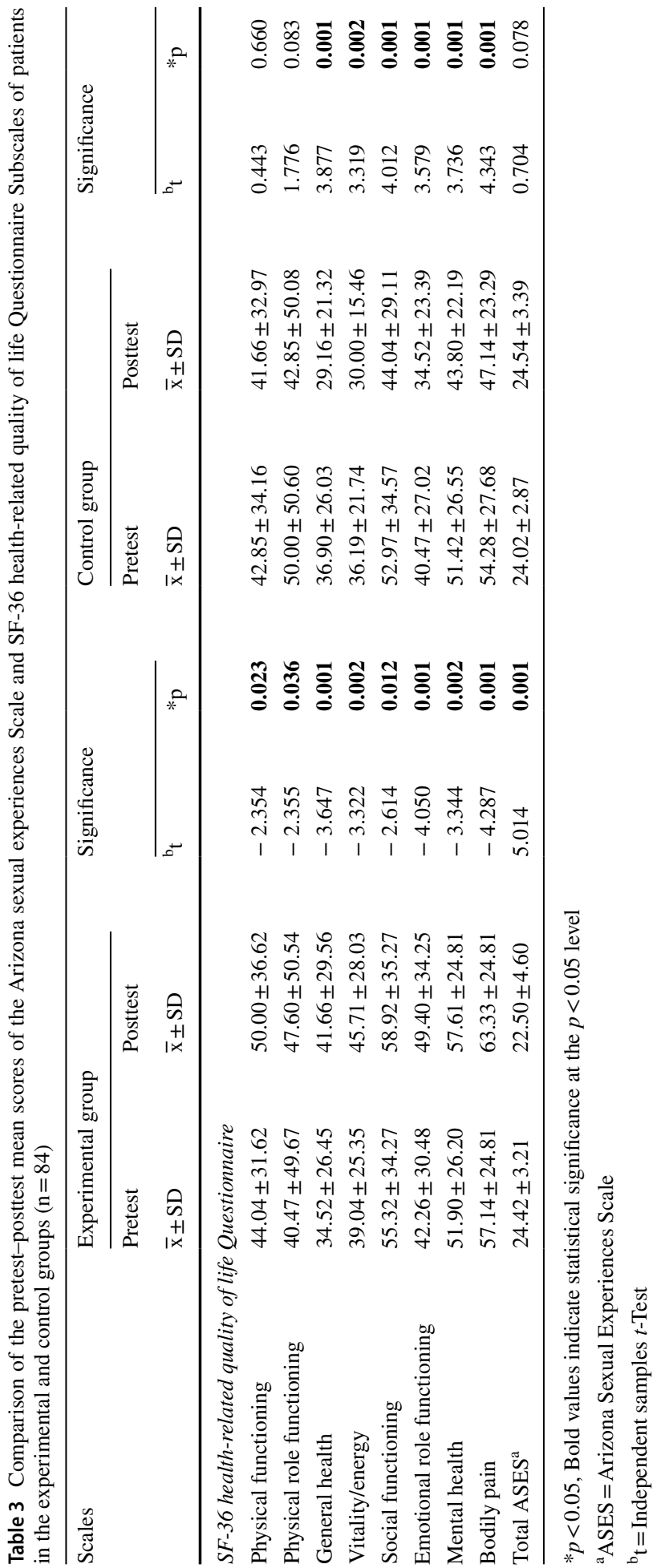


on their sexual experiences and quality of life. This study is the first interventional study interpreting the quality of life and sexual experiences in COPD patients.

\section{The Effect of Nursing Care on Quality of Life of Patients with Chronic Obstructive Pulmonary Disease}

No difference was determined between the pretest to mean scores of the Quality of Life Questionnaire subscales of the patients in the experimental and control groups ( $\left.p^{>} 0.05\right)$; on the other hand, there was a significant difference between the posttest mean scores $(p<0.05)$ (Table 2). Nursing care applied during visits to the experimental group was thought to cause a difference between the experimental and control groups. The high scores of the Quality of Life Questionnaire subscales signify positively affected health conditions. The posttest Quality of Life Questionnaire subscale means scores of the experimental group to which nursing care was applied were affected positively after the nursing care than the control group, and there was an increase in quality of life of patients with COPD. Also, a significant difference was found between the pretest-posttest mean scores of the Quality of Life Questionnaire subscales of the experimental group $(p<0.05)$ (Table 3). This result shows that the posttest Quality of Life Questionnaire mean scores of the experimental group increased.

Quality of life is an indicator of one's physical, psychological and social health and it enables us to measure to what extent the disease affects the patient's daily life, health and happiness [1]. Primarily dyspnoea and pain, sleeplessness, weight loss, dependence on home, social isolation, lack of self-care, frequent applications to hospital and prolonged hospitalizations among COPD symptoms cause severe deterioration in the quality of life [18]. In their experimental study, Karasu and Aylaz [11] found that nursing care applied to COPD patients had a positive and significant effect on patients' meaning of life. The main goal in COPD treatment is to enhance the deteriorated symptoms and quality of life [19]. In their study, Meldrum et al. [20] determined that pulmonary rehabilitation enhanced the quality of life in COPD patients. Another study revealed that health training given to COPD patients provided symptom management and increased quality of life [21]. In their research, Wood-Baker et al. [22] determined that nursing care was effective in managing COPD, reducing hospitalizations, and enhancing quality of life. In a study, it was found that training given to COPD patients within the scope of pulmonary rehabilitation applied at home, provided symptom management and increased quality of life [23]. In a study examining nurses' state of providing care in respiratory system diseases, primarily COPD and asthma, it was indicated that nurses played a vital role in the management of respiratory system diseases [24]. Nurses have an essential place in the application of pharmacological and nonpharmacological treatment approaches [25, 26].

The National Asthma Education and Prevention Program (NAEPP) guidelines state that nurses support effective communication and effective disease management and establish strong communication with their patients. Also, this strong communication is in a critical position in seeing adverse side effects of the disease and providing more care, especially for high-risk patients. Another critical aspect of the effective nurse-patient partnership is that nurses allow training patients on the inhaler, which has an essential place in COPD management [27]. In their study, Ingadottir and Jonsdottir [28] determined that nursing care given to COPD patients at home provided patients and families with education, provided individuals' maximum independence and active participation, allowed them to take responsibility in life, and increased their personal care agency. The fact that these training 
were given by nurses through home visits reduced disease symptoms and applications to hospitals, increased patients' information about the disease, enhanced patients' health condition, developed their functional condition, and enhanced their quality of life [16, 29].

According to the literature, it has been determined that nursing training given to COPD patients increases patients' knowledge level, symptom control, the habit of taking the medication regularly, applying breathing exercise techniques, and quality of life [16, 29]. In this study, it was determined that nursing care applied with four home visits to the experimental group enhanced quality of life in COPD patients positively. Also, it is thought that the training guide which is given to patients and includes the definition, reasons, symptoms, treatment and care of COPD, quitting smoking, proper and regular use of COPD medications, participating in pulmonary rehabilitation programs, coughing and deep breathing exercises, protection from respiratory tract infections, proper nourishment and adequate hydration, use of oxygen therapy, controlling attacks, keeping away from stress, having regular check-ups and arranging daily activities, also made a contribution. In addition to this training guideline, it was thought that nursing care, patient training and counselling provided for problems determined during each visit were effective on symptom control and quality of life. Also, COPD is a disease that affects not only patients but also their families and the environment. Home care applied by nurses whose primary role is the care with a holistic approach (including family) and sustainability of care applied may have increased the individual's sense of independence and contributed to the development of quality of life.

As no nursing care was applied to the control group in the study process, a statistically significant difference was detected between the pretest-posttest mean scores of some subscales of the Quality of Life Questionnaire; however, this difference reduced the posttest mean scores compared to the pretest (Table 3).

Since the Quality of Life Questionnaire mean scores of COPD patients increased after nursing care application, it was thought that the nursing care was effective. Following this result, hypothesis $\mathrm{H}_{1-\mathrm{a}}$, "Nursing care affects the quality of life in COPD patients" is supported.

\section{The Effect of Nursing Care on Sexual Life of Patients with Chronic Obstructive Pulmonary Disease}

In the present study, it was determined that while there was no difference between the pretest ASES mean scores of patients in the experimental and control groups $\left(p^{>} 0.05\right)$, there was a significant difference between the posttest mean scores $(p<0.05)$ (Table 2$)$. This result was thought that nursing care applied during visits to the experimental group caused the difference between the experimental and control groups. There was a difference between the pretest-posttest ASES mean scores of the experimental group $(p<0.05)$ and patients' posttest mean scores decreased. Also, no significant correlation was found between the pretest-posttest ASES mean scores of the control group ( $\left.p^{>} 0.05\right)$ (Table 3). The highest and lowest scores of the scale are 30 and 5, respectively. While low scores signify a strong sexual response, high scores indicate the presence of sexual dysfunction. Accordingly, it is possible to state that the sexual function level of COPD patients included in this study was not good.

There was a decrease in the ASES mean score of the experimental group, who received nursing care throughout the study, during the last visit compared to the first visit. On the other hand, there was no change in the ASES mean score of the control group, during the last visit compared to the first visit. One of the adverse effects of chronic diseases is that 
they affect sexual life negatively [10]. Chronic diseases may damage individuals' sexual functions such as orgasm disorder, ejaculatory incompetence, dyspareunia and suppression of sexual desire and may also cause them to fear sexual intercourse. Besides, medications used for treatment may affect individuals' sexual desires [10, 30]. During home visits to the experimental group, it was found that COPD symptom reducing, deep breathing and coughing exercises, dyspnoea management and energy preservation techniques applied within the frame of the nursing care plan, was valid on increasing patients' Physical Function capacity (the experimental group's pretest mean score of the Quality of Life Questionnaire Physical Functioning subscale was $44.04 \pm 31.62$ and posttest mean score was $50.00 \pm 36.62$ ). The fact that COPD patients feel weak throughout the disease, lack of energy for sexual activity, and their sexual partners avoid sexual activity may affect patients' sexual life. As is known, individuals with lower quality of life have a weaker selfcare agency and a greater need for care. Accordingly, it is thought that the sexual life of COPD patients with less self-care agency and increasing care needs will be affected negatively. Home visits enable nurses to approach patients with a holistic perspective (including family), become individual-centred without ignoring any condition, determine the problems and needs of patients in their comfortable home environment and plan and assess nursing care. Home visits and care applied to patients by nurses may have increased their physical functions and thus affected their sexual life positively.

In the study, a statistical difference was found between the pretest-posttest ASES mean scores of the control group (Table 3).

These results revealed that nursing care applied to COPD patients affected the ASES mean scores positively and was effective. According to this result, the hypothesis $\mathrm{H}_{1-\mathrm{b}}$, "Nursing care affects sexual experiences in COPD patients" is supported.

\section{Conclusion}

Nursing care plays a crucial role in controlling COPD symptoms-primarily dyspnoea, reducing hospitalizations, maximizing patient functions, focusing on teaching personal care skills, increasing exercise capacity, managing the disease, and sustaining quality care.

In this study, it was determined that nursing care increased the sexual experiences and quality of life of the patients. Sustainment of nursing care applied during home visits contributed to COPD patients' quality of life and sexual life. It was found that the sexual experiences and quality of life of patients in the control group decreased. In this context, public health nurses' power of applying critical interventions to COPD patients and sustaining nursing care with home visits is essential in terms of raising awareness in patients, families and caregivers with a professional approach. Public health nurses also have a responsibility to help maximize the quality of life of COPD patients. In home care practices, primary care nurses should focus on the care of COPD patients. Nursing care should be evidencebased, continuous and comprehensive, and accessible by involving families in care. Thus, it is suggested to increase interventional studies on nursing care in COPD patients, and to conduct studies with other patient groups, to assess the effect of nursing care on sexual experiences and quality of life. 


\section{Research Limitations}

The posttest data collection of 17 patients were performed by telephone call due to the coronavirus pandemic.

Acknowledgements We thank all the patients who contributed to this study.

Author Contributions Study conception and design: FK, CBO. Data collection: FK, CBO. Data analysis and interpretation: FK, CBO. Drafting of the article: FK, CBO. Critical revision of the article: FK, CBO.

Funding No support was received to conduct the research.

Availability of Data and Materials Not applicable.

Code Availability Not applicable.

\section{Compliance with Ethical Standards}

Conflict of interest The authors declare that they have no conflict of interest.

Ethics Approval and Consent to Participate Ethical approval was obtained from the Clinical Trials Ethics Committee (Ethics Committee No: 2019/23). Written consent was obtained from the patients to conduct the study.

\section{References}

1. Benzo, R.P., Abascal-bolado, B., Dulohery, M.M.: Self-management and quality of life in chronic obstructive pulmonary disease (COPD): the mediating effects of positive affect. Patient. Educ. Couns. 99, 617-623 (2016). https://doi.org/10.1016/j.pec.2015.10.031

2. Zamzam, M.A., Azab, N.Y., Wahsh, R.A.E., Ragab, A.Z., Allam, E.M.: Quality of life in COPD patients, Egypt. J. Chest. Dis. Tuberc. 61, 281-289 (2012). https://doi.org/10.1016/j.ejcdt.2012.08.012

3. Tel, H., Demirkol, D., Kara, S., Aydın, D.: Care burden and quality of life among the caregivers of patients with COPD. Turk. Toraks Mag. 13, 87-92 (2012). https://doi.org/10.5152/ttd.2012.21. ((Original work published in Turkish))

4. Kocabaş, A., Atış, S., Çöplü, L., Erdinç, E., Ergan, B., Gürgün, A., Köktürk, N., Polatlı, M., Şen, E., Yildırım, N.: Chronic Obstructive Pulmonary Disease (COPD) Protection, Diagnosis and Treatment Report. (2014) (Published in Turkish). https://www.chiesi.com.tr/img/download/documenti/363_ttdkoah-tani-ve-tedav-C4-B0-raporu-2014.pdf.

5. Huijsman, R., Haan, A., Hacken, N., Straver, R.V., Hul, A.J.V.: The clinical utility of the GOLD classification of COPD disease severity in pulmonary rehabilitation. Respir. Med. 102(1), 162-171 (2008). https://doi.org/10.1016/j.rmed.2007.07.008

6. Bella, A.J., Shamloul, R.: Psychotropics and sexual dysfunction. Cent. Eur. J. Urol. 66(4), 466-471 (2014). https://doi.org/10.5173/ceju.2013.04.art22

7. Kupryś-Lipińska, I., Kuna, P.: Impact of chronic obstructive pulmonary disease (COPD) on patient's life and his family. Pneumonol. Alergol. Pol. 82(2), 82-95 (2014). https://doi.org/10.5603/ PiAP.2014.0014

8. Petersen, M., Kristensen, E., Berg, S., Midgren, B.: Long-term effects of continuous positive airway pressure treatment on sexuality in female patients with obstructive sleep apnea. Sex. Med. 1(2), 62-68 (2013). https://doi.org/10.1002/sm2.18

9. Collins, E.G., Halabi, S., Langston, M., Schnell, T., Tobin, M.J., Laghi, F.: Sexual dysfunction in men with COPD: impact on quality of life and survival. Lung 190(5), 545-556 (2012). https://doi. org/10.1007/s00408-012-9398-4

10. Merghati-Khoei, E., Pirak, A., Yazdkhasti, M., Rezasoltani, P.: Sexuality and elderly with chronic diseases: a review of the existing literature. J. Res. Med. Sci. 21, 136 (2016). https://doi.org/10.4103/17351995.196618 
11. Karasu, F., Aylaz, R.: Evaluation of meaning of life and self-care agency in nursing care given to chronic obstructive pulmonary patients according to health promotion model. Appl. Nurs. Res. 51, 151208 (2020). https://doi.org/10.1016/j.apnr.2019.151208

12. McGahuey, C.A., Gelenberg, A.J., Laukes, C.A., Moreno, F.A., Delgado, P.L.: The Arizona Sexual Experience Scale (ASEX): reliability and validity. J. Sex Marital Ther. 26(1), 25-40 (2000). https:// doi.org/10.1080/009262300278623

13. Soykan, A.: The reliability and validity of Arizona Sexual Experiences Scale in Turkish ESRD patients undergoing hemodialysis. Int. J. Impot. Res. 16, 531-534 (2004). https://doi.org/10.1038/sj.ijir.39012 49

14. Ware, J.E., Sherbourne, D.C.: The MOS 36 item short form health survey (SF 36). I. Conceptural framework and item selection. Med. Care 30, 473-483 (1992)

15. Koçyiğit, H., Ömer, A., Fişek, G., Ölmez, N., Memiş, A.: Reliability and validity of the Turkish version of the short form-36 (SF-36). J. Med. Treat. 12, 102-106 (1999). ((Original work published in Turkish))

16. Yu, S.H., Guo, A.M., Zhang, X.J.: Effects of self-management education on quality of life of patients with chronic obstructive pulmonary disease. Int. J. Nurs. Sci. 1(1), 53-57 (2014). https://doi. org/10.1016/j.ijnss.2014.02.014

17. Kahraman, H., Sen, B., Koksal, N., Kilinç, M., Resim, S.: Erectile dysfunction and sex hormone changes in chronic obstructive pulmonary disease patients. Multidiscip. Respir. Med. 8(1), 66 (2013). https://doi.org/10.1186/2049-6958-8-66

18. Norweg, A., Jette, A.M., Ni, P., Whiteson, J., Kim, M.: Outcome measurement for COPD: reliability and validity of the Dyspnea Management Questionnaire. Respir. Med. 105(3), 442-453 (2011). https:// doi.org/10.1016/j.rmed.2010.09.002

19. Abul, Y., Özlü, T.: Turkey’s COPD epidemiology. Curr. Chest Dis. Ser. 1(1), 7-12 (2013). ((Original work published in Turkish))

20. Meldrum, C., Huang, S., Mcinroy, M., Echols, S., Labaki, W., Sagana, R., Han, M.: Increasing pulmonary rehabilitation referrals in COPD patients: a quality improvement initiative. Eur. Respir. J. 54, PA3985 (2019). https://doi.org/10.1183/13993003.congress-2019

21. Almagro, P., Castro, A.: Helping COPD patients change health behavior in order to improve their quality of life. Int. J. Chronic Obstr. Pulm. Dis. 8, 335-345 (2013). https://doi.org/10.2147/COPD.S34211

22. Wood-Baker, R., Reid, D., Robinson, A., Walters, E.H.: Clinical trial of community nurse mentoring to improve self-management in patients with chronic obstructive pulmonary disease. Int. J. Chronic Obstr. Pulm. Dis. 7, 407-413 (2012). https://doi.org/10.2147/COPD.S32220

23. Dias, F.D., Sampaio, L.M., da Silva, G.A., Gomes, É.L., do Nascimento, E.S., Alves, V., Stirbulov, R., Costa, D.: Home-based pulmonary rehabilitation in patients with chronic obstructive pulmonary disease a randomized clinical trial. Int. J. Chronic Obstr. Pulm. Dis. 8, 537-544 (2013). https://doi. org/10.2147/COPD.S50213

24. Spencer, P., Hanania, N.A.: Optimizing safety of COPD treatments: role of the nurse practitioner. J. Multidiscip. Healthc. 6, 53-63 (2013). https://doi.org/10.2147/JMDH.S35711

25. Mwanza, E., Gwisai, R.D., Munemo, C.: Knowledge on nonpharmacological methods of pain management among nurses at Bindura Hospital, Zimbabwe. Pain Res. Treat. (2019). https://doi. org/10.1155/2019/2703579

26. Guerriero, F., Bolier, R., Van Cleave, J.H., Reid, M.C.: Pharmacological approaches for the management of persistent pain in older adults: What nurses need to know. J. Gerontol. Nurs. 42(12), 49-57 (2016). https://doi.org/10.3928/00989134-20161110-09

27. Scullion, J.: The nurse practitioners' perspective on inhaler education in asthma and chronic obstructive pulmonary disease. Can. Respir. J. (2018). https://doi.org/10.1155/2018/2525319

28. Ingadottir, T.S., Jonsdottir, H.: Partnership-based nursing practice for people with chronic obstructive pulmonary disease and their families: influences on health-related quality of life and hospital admissions. J. Clin. Nurs. 19(19-20), 2795-2805 (2010). https://doi.org/10.1111/j.1365-2702.2010.03303.x

29. Fletcher, M.J., Dahl, B.H.: Expanding nurse practice in COPD: is it key to providing high quality, effective and safe patient care? Prim Care Respir J 22(2), 230-233 (2013). https://doi.org/10.4104/ pcrj.2013.00044

30. Yee, A., Loh, H.S., Ng, C.G., Sulaiman, A.H.: Sexual desire in opiate-dependent men receiving methadone-assisted treatment. Am. J. Men's Health 12(4), 1016-1022 (2018). https://doi.org/10.1177/15579 88318759197

Publisher's Note Springer Nature remains neutral with regard to jurisdictional claims in published maps and institutional affiliations. 